\title{
Cultura popular, crítica y política: una lectura a partir de la obra de Roberto Fontanarrosa
}

\author{
Laura Vazquez
}

\section{QUERY SHEET}

This page lists questions we have about your paper. The numbers displayed at left are hyperlinked to the location of the query in your paper.

The title and author names are listed on this sheet as they will be published, both on your paper and on the Table of Contents. Please review and ensure the information is correct and advise us if any changes need to be made. In addition, please review your paper as a whole for typographical and essential corrections.

Your PDF proof has been enabled so that you can comment on the proof directly using Adobe Acrobat. For further information on marking corrections using Acrobat, please visit http://journalauthors.tandf.co.uk/production/acrobat.asp; https://authorservices.taylorandfrancis.com/how-to-correct-proofs-with-adobe/

The CrossRef database (www.crossref.org/) has been used to validate the references. Changes resulting from mismatches are tracked in red font.

\section{AUTHOR QUERIES}

\section{No Queries}




\title{
Cultura popular, crítica y política: una lectura a partir de la obra de Roberto Fontanarrosa
}

\author{
Laura Vazquez \\ Universidad de Buenos Aires (UBA)/Consejo Nacional de Ciencia y Técnica (CONICET)
}

\begin{abstract}
This article seeks to analyze the criticism of Fontanarrosa's work, focusing particularly on political contexts and the specific political position of his critics. The analysis becomes relevant when we observe that Fontanarrosa's work has been studied mostly by critics interested in marginal or in popular culture. Thus, theoretical concepts such as popular and mass become relevant when considering issues linked to national conscience and identity. The study explains how critics of Fontanarrosa's comics revealed his learned parody and underlined the transposition mechanisms (memory, discourse, formats) between popular genres and the media.
\end{abstract}

\section{RESUMEN}

La propuesta de este artículo es partir de la obra de Roberto Fontanarrosa para indagar en las problemáticas nacionales argentinas y las posiciones políticas de los críticos que analizaron su producción. La cuestión es significativa porque fueron aquellos intelectuales interesados en los géneros populares y las producciones marginales de la cultura masiva los que se interesaron en su obra. Como veremos, los diferentes enfoques advirtieron en las historietas de Fontanarrosa un uso letrado y paródico de la cultura. Señalaron, además, una condición múltiple de la memoria de los medios que remite a las transiciones de los géneros populares a los mediáticos, a las dimensiones de la enunciación transpositiva y al juego entre soportes y formatos.

\section{KEYWORDS}

Popular culture; Roberto

Fontanarrosa; criticism;

Argentine identity; media

\section{PALABRAS CLAVE}

Cultura popular; Roberto

Fontanarrosa; crítica:

identidad argentina; medios

Partamos de un dato biográfico: Roberto Fontanarrosa (1944-2007) publicó sus primeros dibujos en la revista Boom (1968) y en el marco de un ciclo histórico complejo de radicalización política y transformación cultural. Simultáneamente, el período de los años 60 y 70 evidenció una retracción en el mercado de historietas y algunas excepciones de la industria abrieron el camino de la experimentación estética y narrativa. ${ }^{1} \mathrm{El}$ desaceleramiento en ciertos espacios del entretenimiento coincide con los vaivenes que tuvieron lugar en los tiempos posperonistas y que afectaron especialmente a las capas medias bajas de la sociedad. ${ }^{2}$ De tal forma que no podría leerse el desajuste entre la "edad de oro" (años 40 y 50) de la historieta y su posterior declive sin atender el contexto histórico en el que se inserta la crisis del mercado nacional editorial.

Es también en esta coyuntura cuando un sector de la crítica convocada por los problemas teóricos prácticos que suscita el análisis de lo popular, encuentra en el 
medio no solo un objeto de investigación sino también de posicionamiento intelectual. Hacia finales de los años 70, los registros de la literatura dibujada en diálogo y tensión con las tradiciones legitimadas de las artes son materia de interés para aquellos referentes ligados a una idea emancipadora de la cultura y para un público adulto ávido de apuestas estéticas y narrativas. ${ }^{3}$

En este contexto, la historieta junto a otros medios de circulación masiva es incorporada a los modernos debates sobre la comunicación y la industria cultural. Un circuito de intelectuales entendían, por entonces, y desde una perspectiva global de los procesos, que era posible contrarrestar la mirada elitista y academicista de la hegemonía "bien pensante" y letrada, para revisitar la experiencia peronista desde una base polémica y, en algunos casos, militante. ${ }^{4}$

Entre el 15 de octubre y el 15 de noviembre de 1968 tuvo lugar en el Instituto Di Tella la Primera Bienal Mundial de la Historieta, co-organizada con la Escuela Panamericana de Arte (EPA). Fue en este marco complejo de fragmentaciones políticas alrededor de la vanguardia y los medios, ${ }^{5}$ cuando la historieta fue pensada por un sector que cuestionaba las prácticas artísticas consagradas, como una estética susceptible de emancipar sus códigos convencionales y producir sobresaltos inesperados e incluso, revolucionarios, en los intersticios de la industria. Se trataba de pensar la dimensión política del arte, por fuera de las instituciones y más cerca de los objetos de la cultura masiva. Fue en ese espacio inaugural, donde intelectuales y profesionales, dibujantes y guionistas confluyeron en un proyecto que tuvo a la historieta como matriz de análisis e instrumento de intervención en lo social.

A finales de la década de los 60, Fontanarrosa no es un dibujante reconocido ni destacado por la crítica aunque ya sus primeras incursiones despuntan un estilo gráfico disruptivo al trabajar sobre el ensamblaje de recursos estilísticos provenientes del grotesco rioplatense, la narrativa popular y la publicidad gráfica. En esta última disciplina, ya había incursionado realizando trabajos freelance en distintas agencias de publicidad. Justamente, entre 1968 y 1969 y con solo 22 años de edad, publica tapas a color y chistes políticos en la moderna revista rosarina Boom. También realizó la sección autoral "Bumor" y dirigió el Departamento de Arte de la publicación. Tratándose de una revista emblemática del llamado nuevo periodismo (cercana a la ya consagrada cosmopolita Primera Plana), Fontanarrosa indagó allí y desde una mirada local en los temas y tópicos del absurdo nacional a partir de renovados giros lingüísticos, la repetición semántica, la revisión de estereotipos y la experimentación gráfica narrativa.

Sin embargo, los fundacionales abordajes de Oscar Masotta, organizador de la Bienal y principal promotor del análisis de la historieta durante los sesenta, no se detienen en la producción incipiente del rosarino. Tampoco en su revista Literatura Dibujada (publicada entre noviembre de 1968 y enero de 1969) presta atención a la ruptura estilística y propuesta temática del autor. Aunque sí le dedicará, por ejemplo, un espacio al virtuosismo plástico de Alberto Breccia para dar cuenta de cómo algunas series funcionaron como parteaguas en el mercado (Mort Cinder) y quebraron las convenciones dominantes de la etapa. ${ }^{6}$

Podría argumentarse que las razones están, en que la obra de Fontanarrosa no constituye, todavía, una obra. O que Masotta no se dedicó al análisis del humor gráfico nacional y puso el acento crítico en la denominada historieta seria o de aventuras y en 
itinerarios de renombre: Hugo Pratt, Héctor Oesterheld, Alberto Breccia. Sin embargo, sí se siente atraído por los trabajos de dibujantes amateurs o carentes de trayectorias en el campo, como es el caso de un joven Copi o del ya reconocido Quino.

Además, y como joven contornista (Masotta había sido parte en la década del 50 del grupo de intelectuales fundador de la revista Contorno) integraba el sector crítico que reelaboró el canon literario desde los márgenes de la cultura. Convocado por la literatura de Roberto Arlt, el lunfardo y la gauchesca, cabe preguntarse por qué un autor como Fontanarrosa pasó desapercibido por su olfato crítico y de avanzada.

Estas referencias abren el interrogante para avanzar sobre las problemáticas de lo nacional y las posiciones políticas de la época. La cuestión es clave dado que permite delinear una hipótesis: no es la "crítica culta" y celebratoria del pop de los 60 la que abona el entusiasmo por el dibujante sino la vertiente de intelectuales comprometidos en el análisis de los géneros populares y las producciones marginales. ${ }^{7}$ De allí que Fontanarrosa inspiró a ese núcleo de la cultura que encontró en la historieta una referencia para el examen de los nuevos relatos y sus múltiples formas de desplazamiento. Siguiendo la lectura de Oscar Steimberg:

El interés teórico y crítico por la historieta empezaba a parecerse al que suscitaban los soportes narrativos y jerarquizados por la cultura: todo to malo y todo lo bueno empezaba a encontrarse en ella. En la exposición internacional/organizada en el Instituto Di Tella en 1968, un nuevo gesto de valoración se manifestó en las numerosas ponencias y mesas de debate: opuestamente a lo que solía ocurrir en el tratamiento dispensado a la historieta en revistas culturales y trabajos críticos, donde era común que apareciera como exponente de una industria cultural adaptativa y enrazadora, en los nuevos espacios se la percibió como espacio de emergencia de la novedad mediática y artística. ${ }^{8}$

En efecto, desde finales de la década se manifestaron discrepancias en la reflexión nacional acerca del lugar que la historieta ocupaba o debía ocupar en el desarrollo popular de las narrativas contemporáneas: suplementos de prensa, catálogos y columnas periodísticas actuaron como lugares de adscripción o diferenciación. Para un sector, la literatura seriada formaba parte de la oferta imperialista de entretenimiento; para otro, un vehículo que en potencia alentaba caminos imprevistos y desvíos impensados en el "núcleo duro" de la industria editorial. Retomando la perspectiva de Pablo Alabarces, estas textualidades periféricas en relación a la institución literaria y academicista, son fundantes de la construcción de un campo de estudios sobre lo popular. Siguiendo su mirada es posible leer en esos abordajes "una periferia posible de ese destino: las anticipaciones, los descubrimientos, los silencios." 9

En este punto, quiero preguntarme si la historieta, y en este mapa de relaciones atravesado por la política, los medios y la crítica, funciona como promotora de nacionalidad al producir narrativas de identidad eficaces. ${ }^{10}$ No parece casual que la producción de Fontanarrosa integre la cantera teórica que sedimenta sus intereses en objetos que van desde las letras de boleros a los guiones de aventuras y las novelitas dramáticas, pasando por los cuentos del policial y la serie negra, las historietas de Hugo Pratt o de Dante Quinterno, la canción de protesta, las semblanzas del star system vernáculo, los libretos y otros intereses laterales al gusto de elite. Fue entonces cuando se inauguró un programa en el que se reivindicaron consumos bastardos al margen del canon literario: 
Como la industria editorial, como la cinematografía, como el tango, como la radio, como el conjunto de lo que acostumbramos a calificar, en suma, como "cultura popular," la historieta argentina parece haber conocido en su conjunto momentos de mayor esplendor consumista, en una lábil franja cronológica que para muchos se extiende desde los años 30 hasta comienzas de la década del 1960, coincidiendo con mayor o menor finura de detalles con el período de eclosión de la industria nacional y con la definitiva configuración de la Argentina urbana y criollo-inmigratoria. ${ }^{11}$

Así, resultaba posible el cruce de temas, estéticas y narrativas en donde lo popular y lo masivo como investigaciones teóricas atravesaban preocupaciones ligadas a la conciencia nacional, la lucha contra el imperialismo y el rumbo común de los pueblos latinoamericanos. Siguiendo la línea de Jorge Rivera, Juan Sasturain lee en esos bordes la posibilidad de una subversión desde prácticas representativas de los valores de los sectores marginales de la cultura. De este modo, la historieta se revela en tanto expresión de identidad y emancipación popular: "Junto a la canción popular, la historieta argentina es acaso la forma marginal que mejor nos define en nuestras posibilidades de crear un medio de expresión propio, auténticamente creador, no dependiente y por lo tanto enriquecedor de nuestra cultura entendida como medio de adquirir un perfil de identidad definido y coherente." 12

No es fortuito que sean estos intelectuales (y no los otros, los identificados por los primeros como pertenecientes a la derecha orgánica) los interesados en la obra de Fontanarrosa. Se trata de una etapa en la que se conforma, a su vez, un área de trabajo alrededor de las literaturas marginales y en donde los analistas precisan ubicarse de un lado o del otro de la contienda. ${ }^{13} \mathrm{Al}$ respecto, la tesis de Mirta Varela resulta sugerente para detectar cruces comunes entre intelectuales como Aníbal Ford, Jorge B. Rivera y Eduardo Romano, quienes buceando en productos y objetos de la cultura de masas pueden dar cuenta de la "presencia de una cultura popular-nacional que tanto la semiología como el marxismo habrían pasado por alto. [...] Estas lecturas de la cultura popular realizadas desde el peronismo son pioneras en incorporar una hipótesis que en la década del ochenta se volvería moneda corriente: la imbricación entre cultura popular e industria cultural."14

La pregunta de Mirta Varela sobre por qué la televisión no fue integrada "a una serie nac \& pop." y, en cambio, fue entendida "como un exponente de transnacionalización de la cultura" 15 abre la cuestión hacia nuestro problema. Me pregunto si la posición política de concebir a la televisión como un "símbolo de la modernización exógena"16 no es extensiva a ciertos géneros de historieta no considerados por aquellos intelectuales populistas vinculados al peronismo. Nuevamente, aquí, la producción humorística y narrativa de Fontanarrosa vendría a funcionar como anillo al dedo para las lecturas de esos años. Podría indagarse por qué una historieta como Boogie, el aceitoso puede inscribirse en una dimensión transnacional mientras que Inodoro Pereyra, no.

Retomando lo señalado, abordaré algunas miradas constitutivas del campo crítico de la historieta argentina y que tomaron la producción del dibujante como argumento tanto de matrices teóricas como políticas. Estos ensayos centrados en la conexión de lo popular con lo masivo se cristalizan en debates con algunas continuidades y coincidencias.

Puntualmente me referiré a los trabajos que entre la décadas del 60 y los 80 signaron el derrotero de la reflexión sobre el medio: Guillermo Saccomano y Carlos Trillo (1980), Sasturain (1995), Steimberg (1977), Rivera (1992) y Romano (1985). ${ }^{17}$ En todos los casos, 
el eje de reflexión estará puesto en Inodoro Pereyra, aunque los autores no circunscriban sus análisis a esta historieta y la vinculen a la obra integral y la trayectoria del dibujante.

En un trazado histórico abarcativo de los años 60-80, se mantiene una constante en los estudios que conectan lo popular con lo masivo y lo masivo con la política: el emplazamiento en una zona intermedia entre la cultura de masas y la marginal, y una lectura en donde la cuestión de lo nacional y la identidad resultan temas nodales. Los enfoques advirtieron en las historietas de Fontanarrosa un uso letrado y paródico y señalaron esa condición de la memoria de los medios que remite al pasaje de los géneros populares a los mediáticos, a las dimensiones de la enunciación transpositiva y al juego entre soportes y formatos. ${ }^{18}$

Siguiendo esta idea, Pablo De Santis ubica la narración humorística del autor en un horizonte común de escritores y humoristas que a partir de la década del 60 renuevan el humor gráfico y literario nacional. Los giros coloquiales extremados hasta el absurdo, evidencian así su carácter destituyente de convenciones y géneros preestablecidos:

Si su primer libro, Los trenes matan a los autos, fue considerado el ejercicio casual de un dibujante, el peso y la continuidad de su obra en sus diversas entonaciones le han dado un dominio sobre la literatura humorística argentina, y a esta última el derecho definitivo a su carácter específico. Tanto en su obra gráfica como en la escritura, Fontanarrosa se acerca al humor de la misma manera: al principio con voluntad paródica y, luego, con la ambición de una autonomía referencial, o sea con una ampliación de registro. Quizás esa independencia respecto del referente sea, por otra parte, la meta secreta de toda parodia que, por otra parte, no intenta separarse del todo de lo que refiere aunque no oculte el deseo de adulterarlo. ${ }^{19}$

Surge entonces un interrogante: ¿es Inodoro Pereyra una historieta popular o una historieta estudiada por intelectuales en clave populista? Y aunque la premisa resulta poco original, quizá convenga retomar la clásica fórmula de Michel de Certeau: “ ¿existe la cultura popular fuera del gesto que la suprime?" 20 Cabe señalar que aquí se entiende la producción de Fontanarrosa como una obra discursiva en tanto el autor no sólo fija una posición de "enunciación artística" sino que al formular su criterio crítico intelectual manifiesta su posición como intermediario cultural. ${ }^{21}$ Sabine Schlickers en su investigación sobre la gauchesca sostiene que y desde finales del siglo XIX hasta nuestros días, el imaginario del género es siempre extensible a otras zonas de emplazamiento. ${ }^{22}$

Siguiendo esta premisa, Inodoro Pereyra como relato mítico contribuye a modelar toda una iconografía contemporánea que ratifica la ficción social alrededor de los gauchos. En esta línea, Guillermo Alén plantea que Inodoro es un caso de historieta aluvional antes que criollista. Esta lectura permite ubicar a la serie de Fontanarrosa en una línea disruptiva de la ya iniciada en historietas clásicas como las realizadas por Enrique Rapela, Carlos Casalla o Raúl Roux, entre los autores más representativos del género. $^{23}$

Esta concepción de los gauchos como tópico de mediación que posibilita la condición paródica del lenguaje es central en la narrativa y en la gráfica del autor. ${ }^{24}$ Pero antes que una parodia del género gauchesco en Inodoro Pereyra, las reglas de verosimilitud del relato están quebradas de antemano: los desvíos buscan señalar que la historieta está en un más allá del género de representación y modelización del arquetipo del gaucho rioplatense. ${ }^{25}$ En otros términos, en la historieta parece que la gauchesca fuese el punto de partida para decir algo distinto al discurso criollista y a la literatura costumbrista. Así, el referente está allí solo a condición de ser desplazado de su centro. 
Por otro lado, partiendo de una circularidad de los consumos entre la literatura popular y la historieta, es posible pensar en las articulaciones que operan en el espacio cultural: Fontanarrosa es el autor modélico que puede atravesar confortablemente géneros y lenguajes (la novela, la historieta, el guión publicitario), y emplazar su obra en un arco temporal y territorial verdaderamente nacional. No podría detenerme en ello, pero el hecho de que haya optado por residir en un sitio ex/céntrico expone una elección de vida (o una estrategia de movilidad en la fijeza) que se resiste a concebir en el circuito porteño, el núcleo centrípeto que irradia hacia los márgenes.

Entre 1974 y 1975, ediciones de La Flor publica Las aventuras de Inodoro Pereyra, ;El Renegáu!, primera recopilación de la serie Inodoro Pereyra. El mismo año y con la aparición de Mengano (Julio Korn), la historieta pasa a esa publicación (1974-1976) al tiempo que Fontanarrosa trabaja paralelamente en las dos revistas. Durante 1974, colabora también en proyectos como Chaupinela (Andrés Cascioli) y la rosarina $\mathrm{La}$ cebra a lunares (Manuel Aranda). En 1975, la serie pasa a editarse en Siete Días por un breve lapso. Entre 1976 y 1980, se instala en Viva, suplemento de Clarín, mientras que en 1980 Boogie, el aceitoso se publica en SuperHum ${ }^{\circledR}{ }^{26}$

El derrotero de la serie forma parte integral de sus meta-referencias no sólo en una dimensión temática y genérica sino también en el plano formal y enunciativo de la obra. Por supuesto, no es una característica aislada del modo de producción de los dibujantes de historieta: una tira como la popular Mafalda de Quino también permite corroborar este tipo de emplazamiento fronterizo intertextual y en relación al contexto en el que se inserta.

Cabe señalar que el tramo recorta un periodo signado por los años de dictadura militar (1976-1983) y que concluye con el retorno de la democracia al país en 1984. Son años, también, en los que la industria dela historieta deja atrás su etapa dorada y resurge tras la represión y la censura en proyectos representativos de las nuevas generaciones y demandas. En este marco, la revista Fierro de historietas ocupará un lugar preponderante.

\section{Márgenes, medios y cultura popular: entradas}

El escritor y crítico Sasturain, desde sus ensayos en la revista SuperHum ${ }^{\circledast}$, primero, y desde la dirección de Fierro después, tendrá un rol central en la difusión de la obra de Fontanarrosa. ${ }^{27}$ Así, publicaba "Siete vueltas alrededor de un Inodoro" (1980), texto reeditado más tarde en El domicilio de la aventura (1995), en el cual revisitaba la cuestión del género gauchesco y sus desvíos. ${ }^{28}$ Se trata de una mirada que celebra las reapropiaciones que los medios populares hacen de los géneros literarios. El ensayo trabaja sobre los alcances de la escritura liminar en donde la institución pierde su fuerza elitista:

Letras rojas sobre fondo azul, gesto fiero y un Mendieta solidario, el séptimo tomo de las aventuras de Inodoro Pereyra, el renegáu que De la Flor ha puesto en los kioscos hace un mes, es un buen pretexto para encarar en un tête-à-tête telúrico con el último hijo reconocido del amigo Fierro. Con ocho años de pata en la pampa con pequeños intervalos, Inodoro es por muchas razones un caso singular: retoma un tema y un ambiente transitados desde el comienzo de nuestra historia cultural - el gauchesco-y al tratarlo en clave humorística, va desarrollando, sucesivamente, diferentes modalidades en una evolución imperceptible pero constante. $^{29}$ 
Centrándose en Inodoro Pereyra y en su itinerario, aborda uno de los aspectos que singulariza el trabajo del dibujante: la adaptabilidad camaleónica a distintos soportes, las regularidades de edición, los formatos y géneros acompañando las oscilaciones de la industria, los emplazamientos mediáticos y la emergencia de nuevos públicos. Siguiendo este razonamiento, la superposición del campo publicitario y el historietístico en el modo de representación del dibujante y del guionista se articula con el sistema de expectativas y las condiciones de producción presentes en otros segmentos de los medios. ${ }^{30}$

Sasturain plantea una genealogía habilitando un enfoque desde el presente y en clave política en donde las resonancias de la voz del gaucho-signo de lo argentino identitario-tienen lugar a partir de cruces entre registros de lo alto y de lo bajo [sic] de la cultura: "Tanto entrecruzamiento de lenguajes, de guiños, de complicidades con el lector, hacen al Inodoro [sic] un producto paradójicamente DIFÍCIL, mediatizado, abierto, nunca esquemático." 31

Al señalar que se trata de un producto exigente busca distanciar la producción de Fontanarrosa de la vertiente dominante de la historieta, representada, por ejemplo, por la escuela de Quinterno o las edulcoradas aventuras de editorial Columba. De allí que Inodoro Pereyra al cruzar registros complejos demanda una actividad intelectual extraordinaria en la industria: segundas lecturas, interpretaciones lúdicas y esfuerzo analítico por parte de su público lector. Para el crítico la fuerza del relato está en el procesamiento insubordinado de los géneros en la cantera siempre versátil de los medios masivos y populares:

La eficacia reside en trabajar sobre mensajes debilitados en su reiteración, sucesión de efectos que carecen de sentido. Porque la parodia, como la caricatura, no hace sino resaltar lo manifiesto: no inventa, enfatiza. En este caso, además, las referencias indirectas múltiples, los guiños constantes al lector, requieren un grado de complicidad y de seguimiento equivalentes a los que piden los poemas de T. S. Eliot o Ezra Pound a los desculadores de la poesía moderna [...]. La cultura popular, la canción argentina y los medios son a Inodoro Pereyra, lo que Virgilio y Homero a Tierra Baldía. ${ }^{32}$

De este modo, como dibujante y como escritor, Fontanarrosa tiene ventajas de intervención estética y en el marco de una tradición que gravita en los contornos de la gauchesca dotándola de relecturas a partir de los recursos específicos de la historieta: la parodia y el grotesco que posibilitan la caricatura, los desvíos en la vertiente de la aventura no realista, el juego con los estereotipos y atributos genéricos, la experimentación y deformación gráfica del desborde estilístico. Sasturain lee en la producción del rosarino una suerte de parodia de la parodia y retomando el capítulo inaugural de la historieta, subraya: que en la primera entrega de Inodoro, Fontanarrosa trabajó sobre la base esquemática del Martín Fierro y que la propuesta se sostuvo en la tensión entre:

la jerga festivalera y nativista de la metáfora ripiosa y oscura de la "savia mineral" [sic] a lo Jaime Dávalos, a lo Tejada Gómez en los trozos narrativos, y el énfasis declamatorio propio del radioteatro en los diálogos. Si "tirao por la vida errante de bohemio" remite al tango Anclao en París, el llanto del crespín a la zamba Trago de Sombra y el final a la despedida de Fierro en la Ida, cuando se aleja de las poblaciones rumbeando para la toldería; si el mismo nombre del personaje se pone en la fila-pero un poco al costado-de los clásicos gauchos-guapos-criollazos: Fierro, Luna, Moreyra, Barrientos, Sombra; todo señala los mecanismos de la parodia, de un texto que evoca otros textos. ${ }^{33}$ 
Sin embargo y para el crítico, la propuesta transgresora de Inodoro Pereyra presente en la revista Hortensia irá degradándose en los tiempos de Mengano y Siete Días, dando cuenta que la serie no tiene idéntica densidad en todos los medios por los que transitó. Al poner atención en los avatares de su publicación, busca subrayar las restricciones que operan en los mercados. En otros términos, mientras que "el primitivo Inodoro" realiza procedimientos a partir del trabajo sobre el repertorio folklórico, literario y poético, la historieta irá perdiendo sus capas de sentido intertextual para optar por la fórmula de tipo continuará:

Cuando Inodoro [sic] emigra de Hortensia a Mengano y luego a Siete Días no sólo cambia de medio sino de modo narrativo. Desaparece la escena aislada, a la manera del encuentro, y aparece la aventura, prolongada de número a número, sostenida por un suspenso artificial que parodia al folletín. Se modifica insensiblemente el lenguaje-la retórica a la manera FOLKLÓRICA se reduce a encabezamientos y finales-y crece una figura fundamental para la existencia de la aventura: el compañero e interlocutor, el otro, Mendieta. ${ }^{34}$

En este sentido, los cercos del género son también los de la industria de los medios. El potencial experimental de la serie no es inagotable sino que está condicionado por los circuitos del campo cultural entendiendo que los cambios de emplazamiento son apuestas estéticas y a su vez, políticas. De allí que la aparición en Clarín resigna su espesor en pos de las circunstancias profesionales de su tránsito mediático. Este "cuarto" Inodoro resigna calidad en pos de su estabilidad genérica. Así, la aventura cede paso frente a la regularidad y seguridad de la propuesta:

Porque este Inodoro [sic] de Clarín [sic] es, sensiblemente, otra cosa. Desde el inicio nomás. El principio, las entregas autoconclusivas-abren y cierran-nos remiten a los primeros tiempos de Hortensia. Pero ahora hay historia andada, tiempo, arraigo. Inodoro está, por primera vez y aparentemente para siempre, anclado: Eulogia, rancho, Mendieta. Los alrededores de la sombra del único arbolito o una corrida hasta el chiquero del rancho solitario son toda la geografía posible. La aventura ha quedado reservada al recuerdo-episodios fortineros que el renegau [sic] evoca épicos-[,] al esbozo de un entrevero. Fontanarrosa ha reflotado el mecanismo de los encuentros pero a partir de un Inodoro quieto, situado, que recibe visitas, ofertas, alguna provocación que soslaya. No le viene a buscar la aventura sino la cotidianidad o la noticia. ${ }^{35}$

Ya sabemos que la estética y narrativa serial ha sido interpretada, históricamente, por los intelectuales como pérdida o versión empobrecedora de la literatura. Por un lado, Sasturain y a contrapelo de las lecturas de Masotta o las del propio Umberto Eco sobre la historieta, recupera en la serie su valor y solidez. Por el otro, traza una interpretación política.

Esta definición tiene su anclaje en un modo de atender las huellas de lo popular en lo masivo y en resaltar la condición periférica y siempre polifónica de los géneros menores. La competencia estilística y temática de Fontanarrosa por la coyuntura (y en la coyuntura) es leída como desventaja simbólica. Es decir, la apuesta por sintonizar con un público cuyos intereses son otros a los de su proposición original y el alejamiento de la aventura por entregas, son juzgados como pasos desafortunados. En el marco de una nueva relación con el público, ya no basada en la complicidad de la parodia intertextual sino en el tratamiento directo de coyunturas diarias "Inodoro se ha desintelectualizado para crecer periodísticamente." Con mecanismos centrados en el juego de palabras, el absurdo y recursos ya utilizados en el chiste de formato unitario, para Sasturain "Inodoro 
Pereyra ha abandonado la secuencia en beneficio del 'gag' instantáneo, que recorre la página como una serie nutrida de disparos livianamente unidos." Sin narración, la historieta deviene chiste, abandonando su épica inicial y acercándose a la caricatura "el renegau [sic] se representa a sí mismo ante los extraños, cancherea ante los turistas, cuenta hazañas sospechosas, no existe casi." ${ }^{36}$

Como si el pasado y el presente estuviesen desgarrados entre la realidad y la ficción o como si el gaucho domesticado, al contribuir con su cordura a la fábula de identidad de la nación, perdiera el deseo y su facultad erótica y libertina. Dominado por su mujer y la cultura patriarcal, repone con ese topos de la literatura popular una lectura conservadora y se vuelve instrumento de coerción. El renegáu va perdiendo su rebeldía (a medida que pasan los años de la historieta y los del sempiterno personaje) y se argentiniza su valor cifrado en la figura de un gaucho folklorizado, nacionalista y, por lo tanto, disciplinado. Si en sus inicios, se trató de una nutrida parodia del gaucho rioplatense y la vida campestre, con guiños críticos a los estereotipos del "hombre de campo," al imaginario del terruño folclórico y a la jerga nativista, ello irá modificándose en función delos emplazamientos editoriales. $^{37}$

En otra línea y en la interpretación de un escritor acerca de otro escritor, se formula un sistema de creencias signado por la escisión entre cultura de elite y cultura de masas. Cabe destacar que mientras que para Sasturain el autor de Inodoro trabaja sobre los sentidos arraigados del gaucho rioplatense y la transposición genérica, como novelista carecería de ese sentido metatextual presente en su gráfica. Destaca así en "The Best of Fontanarrosa," 38 un artículo dedicado a la promoción de su primera novela, que la misma incurre en ciertos lugares culturizantes del registro popular.

Hace rato que el dibujo de Fontanarrosa, sin llegar a empobrecerse, se ha hecho funcional, puesto al servicio mecánico de una palabra cada vez más protagonista. Y si es así en su humor diario, ¿qué decir de 220 páginas sin un solo dibujito? En principio, la novela es más la culminación desmesurada de una modalidad ya transitada-la parodia-que el comienzo de un camino nuevo. ${ }^{39}$

Así, la tensión entre arte y mercado, o literatura e historieta, se zanjaría por la vía de la reivindicación de una supuesta marginalidad. Como cronista del campo historietístico y conocedor erudito de las novedades de mercado, ejerce una hermenéutica sobre los objetos marginales y elabora su tesis con el rigor de un estadista. Tras un racconto por los avatares y momentos de apogeo de la historieta y el humor nacionales subraya:

ha de ser la creatividad de Roberto Fontanarrosa - a partir de esa modalidad que enfatiza los elementos coloquiales-la que decante en personajes definitivos como Inodoro Pereyra y Boogie el aceitoso. Precisamente, el primero de ellos marca emblemáticamente en su paso sucesivo por distintas revistas y un diario, el peso de esa relación inclusiva que hace indisoluble un mensaje del medio periodístico que lo sostiene y le da su contexto, un tema que está en la base de cualquier propuesta realista que afronte el desafío de producir para argentinos en un medio argentino. ${ }^{40}$

En una línea similar y enfatizando el tono coyuntural de la intervención, Trillo y Saccomanno destacan el carácter marginal del producto historietístico, reconstruyen el periplo de apogeo y crisis del mercado en contraposición a la situación internacional y subrayan: 
En Argentina estamos en otra parte. Estamos, por ejemplo, inmersos en otra geografía, en una historieta azarosa, en un mercado constantemente vapuleado por procesos inflacionarios y políticos. En consecuencia, las puertas de la experimentación son más difíciles de franquear. No obstante, los argentinos, a pesar de todo, contamos con casos que, aislados en lo aparente, van indicando una historieta, es decir, un proceso que se teje despacio pero con firmeza para los creadores marginales. ${ }^{41}$

Esta lectura también puede rastrearse en el enfoque del semiólogo Steimberg, cuando señala en 1977 y en el prólogo a su Leyendo historietas la acentuación del carácter periférico de la producción de historietas en la Argentina. Al resaltar unos modos de hacer dependientes del mercado global y en un contexto en donde los dibujantes y guionistas locales exportan, accidentalmente sus productos a mercados internacionales, es posible contrarrestar las deficiencias de infraestructura o medios presentes en otras zonas de la industria del entretenimiento, dado que la historieta sin posibilidades de innovación tecnológica, puede elaborarse en condiciones artesanales: "Habrá que rastrear los efectos en el mensaje de este particular modo de producción artística (¿tan latinoamericano?), según el cual un historietista solitario exporta, a pedido-y a veces, según indicaciones muy precisas-la interpretación gráfica, narrativa $\mathrm{o}$, simplemente ilustrativa de un relato que del otro lado del océano algunos quieren ver. ${ }^{42}$

Cabe preguntarse, entonces, hasta qué punto la obra de Fontanarrosa y específicamente Inodoro Pereyra puede ser incluida en ese corpus de "historietas transnacionalizadas" que a partir de la década de 1970 marcarán el devenir de la industria. En otros términos: ¿puede una serie como Inodoro ser decodificada por públicos internacionales? En contraposición a otras producciones ya clásicas, la de Fontanarrosa supone un problema de exportación y por tanto, parece reforzar esa supuesta identidad en tanto símbolo de un modo de decir y de narrar, de un argentino, para otro argentino.

Sobre la serie, Steimberg propone un intertexto parodiado en tanto el personaje central conlleva un descentramiento poético (antes que psicológico y basado en tipos sociales) y hablado por el gauchismo literario. ${ }^{43}$ Da cuenta, en cambio, de una transformación en el verosímil de costumbres característico de la etapa masiva y de su refundación narrativa. En su artículo "Para una historia de la historieta argentina del humor" 44 señala un "desvío metalingüístico" respecto de la condición de existencia de los personajes en la escena de las literaturas dibujadas. Para el semiólogo, Inodoro Pereyra, parte de las tramas originales presentes en dramas y canciones que conformaron un estereotipo "autóctono," y que son los que determinan siempre, desde un fragmento poético parodiado o una redundancia estilística, su alienación particular. Resalta la acentuación paródica y metapoética de Inodoro Pereyra y su diferenciación respecto de los imaginarios verosímiles del prototipo gauchesco. ${ }^{45}$

El sentido desviante que encuentra en la historieta se trata de una ruptura con respecto a la doxa narrativa y estética del dibujo realista fundado en la caricaturización de tipos sociales, burla costumbrista y enfrentamiento catártico a la historieta humorística. Por otro lado, encuentra en cierto grotesco y en el efecto paródico de la literaturización gráfica del gaucho pampeano el anuncio de la muerte de un tipo de historieta o de un arquetipo de caricatura vigentes en otros segmentos del humor nacional. La transformación de la historieta de humor tiene así, un sentido experimental o, acaso, transformador.

Por supuesto no es la única producción que da cuenta de los resquebrajamientos del periodo anterior. Junto a Fontanarrosa, las historietas y tiras de Caloi, Quino, Copi 
y antes de Calé, Battaglia, Ferro, Oski o Kalondi ya señalaban discontinuidades. En una entrevista, Steimberg pone el foco en el contrapunto del texto y el dibujo en Inodoro, y detecta el componente barroco de su enunciación estilística, preguntándose qué pasaría si Fontanarrosa escribiera y no dibujara, y advirtiendo las características de un dibujo previsible como anclaje de un texto mucho más imprevisible. ${ }^{46}$

Por su parte, los guionistas y escritores Trillo y Saccomano en Historia de la historieta argentina (1980), publicado por Editorial Récord (la misma casa que editaba las revistas más populares del mercado), resaltan de Inodoro Pereyra el carácter paródico de su producción y el tono con el que la serie construye su mixtura entre los registros bajos, medios y altos. Los autores, conocedores de la historieta gauchesca y de diarios masivos, reubican a Fontanarrosa en una serie abarcativa de las tiras de Rapela y su Cirilo el audaz u Hormiga negra de Walter Ciocca, pero también en la línea del folletín, el sainete criollo y el teatro de comedia, las novelas sentimentales y las zambas del folklore nacional. Así, Fontanarrosa realiza con su historieta una parodia que opera sobre los restos de géneros marginales de la literatura y sobre la industrialización del criollismo como materia prima o insumo de los medios: "Inodoro se apellida Pereyra por parte de madre. Y su nombre es Inodoro por su papá que era sanitario. Entre sus antepasados deben estar Héctor Bates y Juan Carlos Chiappe. También Don Rosa, aquel personaje de Mariano Juliá, suerte de Viejo Vizcacha pero sin maldad. YLindor Covas, su pariente realista en la historieta argentina. Y Patoruzú. Y Jaime Dávalos." ${ }^{\prime 4}$

En este cruce en donde aparecen figuras del radioteatro, personajes de la historieta costumbrista de los años de oro de la industria y del poemario popular del folklore, Trillo y Saccomanno buscan evidenciar que Inodoro Pereyra trabaja sobre el canon y los desechos del sentido estabilizado. Lejos del respeto por su figura arcaizante y telúrica (materializada en la antinomia civilización y barbarie), el dibujante pone en jaque el género criollista parodiando hasta sus límites el imaginario nacional y literario. En un contrapunto con la producción de Caloi y sobre el trasfondo del humor gráfico de la década de 1970, subrayan: "Un dibujante rosarino. Un hincha de Rosario Central. El humorista argentino que mejor maneja las historias largas. El gran parodista. El admirable creador de dos historietas que recogen elementos del doblaje de las series, del folklore más engolado y retórico, de los tíos del folletín decinomónico y de la serie negra, de la radio que escuchábamos cuando éramos pibes y de las películas de nuevo cine americano." 48

Como si la solución de la extranjería (un escritor en las orillas del mapa literario) atravesara las contradicciones del campo y la ciudad, en tensión con lo moderno y los mitos del pasado hispano-criollo, tanto Romano como Rivera destacan la trama intertextual de la historieta, señalando que retoma motivos tradicionales y añade nuevas modulaciones características de los medios masivos. ${ }^{49}$ Con agudeza, Romano señala que la materia prima de Inodoro Pereyra es el cruce de textos literarios ya clásicos (José Hernández, Ricardo Güiraldes, Lucio V. Mansilla) con "el amaneramiento criollista de algunos locutores radiales, sobre todo en ocasión de ciertos festivales" el uso de un repertorio musical típico de "el cancionero 'folklórico' que divulgan los medios."50

Sin embargo y ahí su apuesta teórica desde una posición intelectual que lee la cultura desde los medios y los medios desde lo popular, Romano enfatiza que la amalgama de exploraciones tildadas de altas y bajas en la historieta tiene distintos alcances. ${ }^{51}$ Así, la música neo folklórica en mixtura con las películas camperas exitosas tiene más peso 
que la cita erudita de la literatura gauchesca ocupando mayor densidad en la parodia la referencia a los medios, sus nuevos géneros y repertorios estilísticos. En este sentido, los guiones de radioteatro y la moda de los festivales (característicos del interior del país y de la zona pampeana) ocupan el centro de las alusiones intertextuales y rodeos polifónicos:

[El] boom del folklore, en los '60, incentivó la producción poética para ese cancionero (Jaime Dávalos, Armando Tejada Gómez, Ariel Petroccelli, Hamlet Lima Quintana, etc.) y, al mismo tiempo, los tópicos retóricos nativistas, por ejemplo en las presentaciones y glosas del festival de Cosquín. Eso es lo que Fontanarrosa ridiculiza, aunque eventualmente mezcle citas del Martín Fierro, de La Cautiva de Güiraldes. En el nivel verbal hubo un progresivo ajuste, similar al ocurrido en el dibujo: es una posibilidad de la historieta seriada de que carecen otros géneros y, por supuesto, la literatura. Así, el empleo inicial de frases provenientes del tango ... sólo fue conservado si se trataba de tangos o milongas camperas: A la luz del candil, Malón de ausencia, Los ejes de mi carreta, etc. ${ }^{52}$

Rastrea en la serie una genealogía inminentemente popular y masiva, y un reconocimiento del propio autor a ese linaje de novelitas de folletín, literatura policial y poéticas de literaturas marginales. De allí que Romano resalte, a pesar de las circunstancias de su publicación, la combinación estilística y la apuesta ideológica de la historieta. Si en la revista Mengano las aventuras eran extensas y a color, en el diario Clarín la misma debe ajustarse al contexto de actualidad e interpelar a su público desde un "encuadre restringido" al contrato de lectura del género. ${ }^{53}$

En esta línea, Rivera en su Historia del humor gráfico argentino tras describir el extenso periodo 1900-1975, también se detiene en la producción de Fontanarrosa y en su historieta Inodoro Pereyra. ${ }^{54}$ Rivera valora positivamente una obra equilibrada estética y narrativamente, ponderando tanto el texto como el dibujo al destacar su calidad y ventajas comparativas.

Publicado en el año 1976 y en el contexto de la última dictadura militar, el texto busca pronunciarse para develar las condiciones históricas de una falacia ideológica. Así, lo nacional-popular no sería aquello que la ideología dominante propone a través de postulados (la simpleza y felicidad del hombre de campo) y toda una cosmovisión de lugares comunes entramados en la cultura oficial sino, las prácticas y saberes de los sujetos comprometidos con su entorno; los antihéroes anónimos que al igual que Inodoro, son víctimas del sistema opresivo del capitalismo y la industrialización:

No cabe duda que el rosarino Carlos Alberto Fontanarrosa, ex creativo de una importante firma publicitaria, es uno de los dibujantes más representativos de este momento, con el talento humorístico de Quino y la ventaja de poseer un dibujo más rico desde el punto de vista plástico ... y al mismo tiempo una plausible capacidad para urdir textos literarios. [...] Inodoro ubicado en una vieja tradición de caricaturización del gaucho, es un intento positivo en lo que tiene de crítica al pintoresquismo folklórico y a la visión falazmente "gauchista" de nuestra cultura nacional-popular. ${ }^{55}$

A ello agrega que el personaje revela a partir de un absurdo liberador "a veces cáustico y desesperanzado, a veces crítico, por momentos reintegrador, en muchas ocasiones ambiguamente rebelde" sus características irónicas e informativas. ${ }^{56}$ En este sentido, sugiere en el devenir de la serie una toma de posición del autor respecto del contexto. Así Inodoro y como representante de los sectores más relegados de la cultura, sienta las bases "de una obstinada afirmación de su solitaria dignidad de hombre despojado, desgajado, marginado en el seno de una sociedad que ha comenzado a ignorar a su sujeto." 57 
Para concluir este apartado: en 2007 con motivo del fallecimiento de Fontanarrosa, Steimberg realiza una reflexión a propósito de las efemérides que circularon en los diarios porteños ese año, sintomáticas de un estado de la cuestión. Bajo el título "Ahora que pasaron: sobre los homenajes a Fontanarrosa," sostenía que primó en ellas cierta jerarquía de los géneros y de los lenguajes, la carga calificativa del escritor por sobre el historietista y la poca atención o desmerecido cuidado a ese transitar por los bordes de su trayectoria. ${ }^{58} \mathrm{Y}$ subrayaba:

No me parece que en alguna nota se haya hablado con la extensión merecida sobre Inodoro Pereyra, una historieta que nos pasa por delante, bailando y dando vuelta, los estereotipos del gauchesco escolarizado. Uno lo lee y recuerda de qué está hecho literariamente (uno mismo) y se atreve a tomar distancia de la repetición sin creación, porque se siente habilitado por la gracia de una contrapayada nueva todo el tiempo. Y para qué están las tradiciones, si no para jugar con ellas como sólo puede hacer el que las tiene. ${ }^{59}$

\section{A modo de síntesis}

Hay algo allí que agrupa a los intelectuales y los asemeja aún en sus diferencias. Posiblemente ello se deba a que la obra de Fontanarrosa sea permeable a querellas teóricas e ideológicas sedimentadas a lo largo de los años. La producción de este narrador y dibujante se articula con esa zona periférica de los medios cuyos andariveles trazan operaciones paradójicas: autor de públicos populares y altos, autor clásico y marginal, consagrado y siempre desplazado de su centro. Su personaje, Inodoro Pereyra, ese gaucho insufrible de la crítica nacional, tiene los atributos de un rebelde imperturbable que (y como el Martín Fierro) cuando va parece que vuelve y cuando vuelve, parece que va. ${ }^{60}$

Es una producción nómada en tanto circuló por distintos medios y en contextos históricos diversos. Por supuesto que el Inodoro de la revista cordobesa Hortensia a principios de los años 70 difiere del publicado en el diario Clarín y durante los años de la dictadura. No fue mi intención detenerme en los rasgos estilísticos, temáticos y retóricos de la historieta ni en cada etapa de su publicación.

Como vimos, la historieta trabaja sobre los tópicos que giran en torno a los dramas nacionales y la construcción ficcional de la identidad argentina, reinventando los géneros en clave cultural. Lejos de una lectura esencialista, extrae distintas fórmulas para ofrecer líneas centradas en pares dicotómicos y complementarios. Es precisamente en las junturas de un amplio sistema de referencias donde pueden establecerse dislocaciones entre el gaucho Inodoro, el payador Martín Fierro de Hernández, el indio Patoruzú de Quinterno o el Harry el sucio en la piel de Clint Eastwood, registros polifónicos y luxaciones narrativas que reelaboran la realidad y la ficción y las vuelven un territorio aventurable cerca y lejos de la mentada identidad nacional. Sobre el carácter paródico de la trama, García Canclini, uno de los pensadores más influyentes sobre las culturas populares, ya había señalado tras realizarle una entrevista personal al dibujante en 1988, que Inodoro Pereyra reactualiza el lenguaje folklórico de canciones y leyendas gauchescas, del radioteatro y los programas televisivos sobre "la identidad nacional" en una trama que atraviesa tanto géneros como épocas. Revisita desde 1972, los tópicos kitsch de la temática folklórica y acentúa desde la parodia los giros lingüísticos y los estereotipos visuales de lo gaucho. Así, Fontanarrosa pone en escena que la exaltación telúrica siempre es desmedida en su versión masiva, conservadora y promotora del folklore nacional. ${ }^{61}$ 
En este sentido y antes que una historieta popular, se trata de una producción que desde el centro alude a una marginalidad que es, a su vez, genérica y geográfica. Cierto tono de extranjeridad se percibe a lo largo de la serie, o mejor dicho, cierta posición de extranjeridad en los bordes mismos del mapa y el territorio: como si Rosario (en contraposición a Buenos Aires) fuese una locación que habilitase la extraterritorialidad $y$, por tanto, la otredad satírica. Inodoro parece estar dibujado por un exiliado argentino o un extranjero que lo ha leído todo sobre Argentina y que puede, en ese caso, dedicarse al juego gozoso de la ficción que desmonta tradiciones desde el pastiche. Como subraya Steimberg y en torno a los efectos del género humorístico, la condición hipertextual del humor y la ironía es inseparable de su similar carácter de discurso sobre discursos, pero mientras que la sátira asienta esa condición hipertextual en la objetivación de los enunciados de un tercero, "el pastiche, si bien juega también con textos (verbales y visuales) ya circulados por la cultura, prioriza su emplazamiento en el régimen lúdico por sobre la crítica o el documento."62

En el espacio rural del gaucho, Inodoro se mueve como un ciudadano cosmopolita y reactualizado. Preocupado por los males de la modernidad, es anacrónico por naturaleza o un desplazado permanente de su centro: Fontanarrosa construye un personaje metaficcional que pone en abismo su sentido para colocarse en la frontera o el deslinde del género, de los medios, de la crítica y, por supuesto, de sus instituciones y empresas. De allí que, y por momentos, la tira pareciera querer decirlo todo sin asumir ninguna posición determinada: asoman en ella conflictos del pasado y del presente en el habla marginal de un gaucho imposible y de ese Otro, que es siempre un silenciado.

Mediante la mezcla de lugares comunes y actualizaciones de la literatura, la historieta, el cine y los medios, la serie se organiza en una zona flotante entre la ficción y la realidad. Inodoro Pereyra trabaja en esa bisagra de tiempos y problemas que ponen en conversación determinados mitos y creencias, y ello suscita, como no podría ser de otro modo, enfrentamientos que ponen en tensión la labilidad de los contornos genéricos.

En definitiva, se trata de pensar la producción para poner a prueba las disquisiciones del medio, reinventar sus motiyos y contratos de lectura, ajustar, negar o discutir las convenciones emplazadas de los estilos y géneros en la cultura contemporánea e indagar en las improvisaciones del humor gráfico que con sus efectos de sentido y sus proposiciones siguen dando lugar a la aventura de un razonamiento inacabado, inusitadamente político.

\section{Notas}

1. Para un análisis de la retracción del mercado de la historieta, ver Jorge B. Rivera, Panorama de la historieta en la Argentina (Buenos Aires: Coquena Grupo Editor, 1992). Oscar Steimberg, Leyendo historietas: textos sobre relatos visuales y humor gráfico (Buenos Aires: Eterna Cadencia, 2013). Guillermo Saccomanno y Carlos Trillo, Historia de la historieta argentina (Buenos Aires: Récord, 1980). Juan Sasturain, El domicilio de la aventura (Buenos Aires: Editorial Colihue, 1995). En continuidad, he investigado los rasgos de una industria oscilante entre las reglas del arte y las del mercado, en Laura Vazquez, El oficio de las viñetas: la industria de la historieta argentina (Buenos Aires: Paidós, 2010).

2. Para más detalles, ver Jorge B. Rivera, El escritor y la industria cultural (Buenos Aires: Atuel, 1998). 
3. Sigo aquí la lectura de Jorge Rivera planteada en Panorama de la historieta en la Argentina (Buenos Aires: Coquena Grupo Editor, 1992).

4. Hay un artículo fundamental para analizar la cuestión de los estudios que "inventan" la cultura popular como objeto y tópico de trabajo intelectual. Ver Pablo Alabarces: "Un destino sudamericano. La invención de los estudios sobre cultura popular en la Argentina," Revista Argentina de Comunicación I, no. 1, 2006.

5. Para una ampliación de este problema ver el trabajo ya clásico de Oscar Terán, Nuestros años sesenta. La formación de la nueva izquierda intelectual en la Argentina (Buenos Aires, Puntosur, 1991) y, del mismo año y en clave polémica, el de Silvia Sigal, Intelectuales y poder en la década del sesenta (Buenos Aires, Puntosur, 1991). En años más recientes, el trabajo de Ana Longoni problematiza las disputas de una época y sus legados: Vanguardia y revolución. Arte e izquierdas en la Argentina de los sesenta-setenta (Buenos Aires, Ariel, 2014).

6. Mort Cinder fue publicada en la segunda época del semanario Misterix de editorial Yago entre 1962 y 1964. Masotta publica una entrevista realizada a Alberto Breccia en el tercer y último número de la revista $L D$ y dedica una reflexión crítica sobre su trabajo.

7. Aunque el problema exceda el fin de este ensayo, cabe citar Carlos Altamirano, Bajo el signo de las masas (1943-1973) (Buenos Aires: Biblioteca del Pensamiento Argentino, T. VI, Ariel, 2001) y Beatriz Sarlo, La batalla de las ideas (1943-1973) (Buenos Aires, Biblioteca del Pensamiento Argentino, T. VII, Ariel, 2001). Para Sarlo, los años que recortan el periodo "fechas marcadas por el surgimiento, la caída, la proscripción y el regreso del peronismo" permiten rastrear el discurso y recorrido de la intelectualidad argentina. Cita de: Sarlo, $\mathrm{La}$ batalla de las ideas (1943-1973), 14.

8. Oscar Steimberg, "La nueva historieta de aventuras: una fundación narrativa," en Historia crítica de la literatura argentina: vol. XI - La narración gana la partida, ed. Elsa Drucaroff (Buenos Aires: Emecé, 2000), 536.

9. Pablo Alabarces (en colaboración con Valeria Añón y Mariana Conde), "Un destino sudamericano: la invención de los estudios sobre cultura popular en la Argentina," Revista Argentina de Comunicación 1, no. 1 (2006): 23.

10. Pablo Alabarces, retomando la tesis de Sarlo señala que "el fútbol funcionó a lo largo del siglo XX como un fuerte operador de nacionalidad, como constructor de narrativas nacionalistas pregnantes y eficaces, en general con un alto grado de coherencia con las narrativas estatales de cada periodo." Pablo Alabarces, Fútbol y patria: el fútbol y las narrativas de la nación en la Argentina (Buenos Aires: Editorial Prometeo, 2002), 20. Ver para más referencias: Beatriz Sarlo, La máquina cultural: maestras, traductores y vanguardistas (Buenos Aires: Ariel, 1998).

11. Rivera, Panorama de la historieta en la Argentina, 6.

12. Sasturain, El domicilio de la aventura, 51 .

13. Para más referencias: Oscar Masotta, La historieta en el mundo moderno (Barcelona: Paidós, 1982).

14. Mirta Varela, "Intelectuales y televisión: historia de una relación," Revista Argentina de Comunicación 1, no. 1 (2006): 52.

15. Ibid., 53.

16. Ibid.

17. En lo posible, cito las primeras ediciones mientras que en el caso de las antologías que recogen publicaciones originales (Sasturain, Steimberg) consigno el año de la compilación.

18. Al respecto es central el trabajo de Oscar Steimberg y sus proposiciones sobre el género y el estilo reeditadas en Oscar Steimberg, Semióticas: las semióticas de los géneros de los estilos, de la transposición (Buenos Aires: Eterna Cadencia Editora, 2013). Hay que señalar, además, que su investigación es ineludible para cualquier tratamiento del lenguaje historietístico y su reflexión sobre la experiencia estética y remisiones intermediales.

19. Pablo De Santis, "Risas argentinas: la narración del humor," en Historia crítica de la literatura argentina: vol. XI - la narración gana la partida, ed. Elsa Drucaroff (Buenos Aires: Emecé, 2000), 500.

20. Michel De Certeau (en colaboración con Dominique Julia y Jacques Revel), "La belleza del muerto: Nisard," en La cultura en plural (Buenos Aires: Nueva Visión, 1999), 69. 
21. Véanse las distintas concepciones teóricas sobre el concepto de intermediario cultural a partir de las categorías de la sociología de la cultura y los aportes de la sociología de los intelectuales en Carlos Altamirano, "Intelectuales," en Términos críticos de sociología de la cultura (Buenos Aires: Paidós, 2002).

22. La autora construye a un corpus amplio para sostener una hipótesis reveladora:

El análisis de las reescrituras y parodias de Borges, Fontanarrosa, Filloy, Sáenz y Bolaño demuestra la trayectoria del gaucho al guapo, de la pulpería al café, de la pampa al barrio porteño $y$, finalmente, el camino inverso del ciudadano que se dirige a la pampa, agauchándose. No obstante, estos textos literarios narrativos hacen surgir la cuestión de si es dable incluirlos en el género gauchesco: todos transgreden los límites del canon al introducir a nivel del contenido elementos nuevos, sorprendentes, extraordinarios y carecen incluso del personaje arquetípico del gaucho, sustituyéndolo por el compadrito, guapo o ciudadano agauchado. Cita de: Sabine Schlickers, "Que yo también soy pueta": la literatura gauchesca rioplatense y brasileña (siglos XIX-XX) (Vervuert. Ediciones de Iberoamericana, 2007), 232.

23. Guillermo Alén, "Inodoro Pereyra: una gauchesca de la posmodernidad," IX Congreso Argentino de Hispanistas, 27 al 30 de abril de 2010, La Plata. El hispanismo ante el bicentenario. Disponible en Memoria Académica: http://www.memoria.fahce.unlp.edu.ar/ trab_eventos/ev.1022/ev.1022.pdf

24. Resulta ejemplar en este punto el análisis de Schlickers en contrapunto de la reescritura de la gauchesca de Borges y de Fontanarrosa, trabajando en detalle con el episodio "La pampa de los senderos que se bifurcan," una torsión paródica del título original.

25. Josefina Ludmer, El cuerpo del delito: un manual (Buenos Aires: Eterna Cadencia, 2011).

26. Ver datos biográficos y de obra del autor en Judith Gociol, ed., Roberto Fontanarrosa: archivos clasificados (Buenos Aires: Biblioteca Nacional, 2017) y en Roberto Fontanarrosa, 20 años con Inodoro Pereyra (Buenos Aires: Ediciones de la Flor, 2001).

27. No podría detenerme pero entiendo que la imbricación de la producción literaria de Sasturain y la de Fontanarrosa, así como las lecturas del primero y las relaciones trazadas en torno al género policial o el tratamiento de distintos tópicos de la identidad argentina como el idioma, el tango, el fútbol, y sin duda, el peronismo amerita una discusión específica. Resulta así, un interés pendiente.

28. El mismo fue publicado originalmente en SuperHum ${ }^{\circledR}$ en diciembre de 1980.

29. Sasturain, El domicilio de la aventura, 193.

30. He trabajado esta problemática en Vazquez, El oficio de las viñetas, 6. Las hipótesis sobre esta movilidad en la escena de la industria cultural pertenecen a Sarlo, La imaginación técnica: sueños modernos de la cultura argentina (Buenos Aires: Nueva Visión, 2004). Por supuesto que el carácter móvil de la cultura en los años de referencia ha sido desarrollada extensamente por la crítica, especialmente por la historia de los medios y la cultura.

31. Sasturain, El domicilio de la aventura, 196.

32. Ibid., 195, negrilla original.

33. Ibid., 194, negrilla original.

34. Ibid., 198.

35. Ibid., 200.

36. Ibid., 201.

37. Judith Gociol, "Inodoro y su tata," en el libro: Roberto Fontanarrosa, 20 años con Inodoro Pereyra (Buenos Aires: Ediciones de la Flor, 2001), 9.

38. El texto fue publicado en el número 6 de la revista (1981) y reeditado en El domicilio de la aventura, 1995. En 1981, Pomaire publica Best Seller y el mismo sello edita al año siguiente su secuela, El área 18. En 1982 De la Flor publica los cuentos reunidos en El mundo ha vivido equivocado.

39. Sasturain, El domicilio de la aventura, 93.

40. Juan Sasturain, "La marginalidad no es un tigre de papel," en Historia de la historieta argentina, ed. Guillermo Saccomanno y Carlos Trillo (Buenos Aires, Récord: 1980), 187. 
41. Saccomanno y Trillo, Historia de la historieta argentina, 181.

42. Steimberg, Leyendo historietas, 19.

43. Ibid., 262.

44. El ensayo fue publicado en Todo es historia (Buenos Aires: 1982) y reeditado en Leyendo historietas, 2013.

45. Steimberg, Leyendo historietas, 256-57.

46. La misma fue realizada por Sanyú y Marcos Mayer y publicada en Brecha, Montevideo, noviembre de 1982. Se reprodujo bajo el título "Un lenguaje con historieta," en Steimberg, Leyendo historietas, 341.

47. Saccomanno y Trillo, Historia de la historieta argentina, 170-71.

48. Ibid.

49. El artículo de López Badano que trabaja de manera contrastiva cierta zona de la producción de Fontanarrosa y Bolaño resulta un texto sugerente para pensar este problema, ver Cecilia López Badano, "Elementos massmediáticos y cultura popular en dos textos de Roberto Bolaño," CELEHIS-Revista del Centro de Letras Hispanoamericanas 19, no. 21 (2010), 20934.

50. Eduardo Romano, Literatura/cine: argentinos sobre la(s) fronteras(s) (Buenos Aires: Catálogos Editora, 1991), 13.

51. No es un dato menor subrayar que Romano asume como Director Provisorio de la Carrera de Letras de la Universidad de Buenos Aires en 1973 y en este contexto, la historieta como objeto fue incluida en el Programa de Literatura Argentina Proyectos políticos culturales del mismo año, materia dictada en la Facultad de Filosofía y Letras. La cátedra estaba a cargo de Romano y Rivera. En la misma, Sasturain ocupaba el cargo de Jefe de Trabajos Prácticos.

52. Romano, Literatura/cine, 276-77.

53. Ibid., 278.

54. Los fascículos fueron publicados originalmente en la revista Crisis, en los números 34 y 35 de febrero y marzo de 1976 y republicados como Jorge B. Rivera, "Historia del humor gráfico argentino," en Medios de comunicación y cultura popular, ed. Aníbal Ford, Jorge B. Rivera y Eduardo Romano (Buenos Aires: Legasa, 1990).

55. Ibid., 135.

56. Ibid.

57. Ibid., 136.

58. La lectura de Steimberg enlaza con el artículo de Federico Reggiani en donde repasa los prólogos realizados por escritores e intelectuales, para las historietas incluidas en la Biblioteca Clarín de Historietas (2004) y en la Nueva Biblioteca Clarín de Historietas (2006). Fontanarrosa realizo las presentaciones para Patoruzú, Ticonderoga y Sherlock Time. Federico Reggiani, "Quisiera ser literatura: el prólogo como recurso de legitimación en la edición de libros de historieta en Argentina: el caso de la Biblioteca Clarín de la Historieta," VII Congreso Internacional Orbis Tertius de Teoría y Crítica Literaria (La Plata: 2009).

59. Oscar Steimberg, "Ahora que pasaron: sobre los homenajes a Fontanarrosa," Revista electrónica del área de crítica de arte del Instituto Universitario Nacional del Arte 2 (oct. 2007), 5.

60. La referencia es Roberto Bolaño, El gaucho insufrible (Buenos Aires: Anagrama, 2005).

61. Néstor García Canclini, Culturas híbridas: estrategias para entrar y salir de la modernidad (México: Grijalbo, 1989), 318.

62. Steimberg, Leyendo historietas, 185. 